\title{
REARING ANIMALS IN CAPTIVITY FOR THE STUDY OF TREMATODE LIFE HISTORIES. II.
}

\author{
By Miriam Rothschild
}

\section{INTRODUCTION}

The advantage of using laboratory-reared animals in the elucidation of trematode life histories is now generally recognized (Palombi, 1938; Stunkard, 1938, etc.). Further researches seem to emphasize this point. No matter how carefully controls are examined and no matter how precise is the morphological comparison between cercaria, metacercaria and adult fluke, the fact that the intermediate and final hosts have been exposed to previous infection in the wild - particularly by closely related species of worms-immediately detracts from the value of the experiments.

The successful efforts at hatching the black-headed gull in an incubator (Rothschild, 1936) led to the entirely erroneous assumption that the herring gull would prove an equally simple proposition. It is thought worth while publishing these practically negative results in case other workers should feel tempted to try a similar experiment.

The stoats, which were required for a dual purpose, were more easily reared than was anticipated. The repeated failure of infection experiments with white rats and various farmyard birds seemed to indicate that better results are obtainable with wild than domesticated animals; ferrets would otherwise have been selected as easier to rear and handle. The stoats proved most attractive and interesting animals to keep and served to illustrate the fact that the helminthologist must guard against the rival attraction of host over parasite.

\section{Larus argentatus Pontopp.}

Observations were begun on a colony of nesting herring gulls before laying commenced. It was thus easy to collect fresh eggs. Two dozen were taken soon after laying and transported by car, the journey lasting $\mathrm{I} 2$ hours. The eggs were then treated in precisely the same manner as those of the blackheaded gull (Rothschild, I936). All failed to develop, the contents remaining in a liquid state.

The shell of the herring gull's eggs appeared less fragile than that of the black-headed and it was thought that these might be incubated successfully by a hen. The following season, therefore, a further collection was made and a score of eggs equally divided between two hens. The majority of these were smashed by the hens, and the rest again failed to develop.

During the autumn, special "cross-bred" bantams were reared, which although retaining the staid sitting qualities of the larger breeds of domestic 
fowl, were of much lighter build. It was also considered possible that eggs of the herring gull sustained internal injury more easily than those of the blackheaded and that a car journey involved too much shaking. The next batch of eggs was consequently conveyed by train and the box containing them held by an obliging passenger, thus avoiding any sudden jars or jolts. On this occasion there had been no opportunity for observing the colony of gulls before laying began, and it seems probable, in the light of subsequent events, that some of these eggs were not fresh. They were separated into three lots, two dozen of which were placed in an incubator, and twenty-four more divided between two cross-bred bantams. Each day, while the hen was feeding, one of the latter groups was heavily sprayed with water. Once again, all the eggs in the incubator failed to develop. Nineteen of the eggs under the bantams were smashed. Chicks developed in the remaining five eggs. Four died immediately before hatching between the I2th and I5th day, and the fifth hatched on the I4th day.

These experiments seem to suggest that there is a slightly better chance of hatching herring gull's eggs if they are collected some while after laying. It appears that a more practical method, provided a gullery is situated conveniently, is to allow the birds to incubate their own eggs and collect them immediately before hatching. Although there has been no opportunity to test this method personally, yet two experienced aviculturists have assured me that it has proved satisfactory. Six eggs of the common gull (Larus canus L.) and the arctic tern (Sterna paradisaea Brünn.) also failed to develop.

\section{Larus ridibundus $\mathrm{L}$.}

Since 1936 four dozen of these birds have been reared every season and the number of chicks hatching successfully has increased by $50 \%$. This is probably due to the fact that the eggs have been thoroughly soused with warm water twice a day. In the original experiments the chamber and the eggs themselves were undoubtedly kept too dry. It has since been learned that when attempting to hatch grebe's eggs in captivity, certain aviculturists actually float the eggs continuously in warm water within the incubator. In nature, even when nesting well away from the water, the black-headed gull probably settles down on her eggs with drops of moisture on the breast feathers.

Some difficulty was experienced in feeding infected fish and crabs to those birds which had previously been accustomed to cooked, hashed-up food only. It has proved useful to familiarize them with solid hard pieces of food, particularly the size and shape of small fish, before feeding experiments begin. When only a few cysts are available it is best, whenever possible, to use young birds which can still be fed easily from the hand and are at the stage when they swallow wholesale anything that is offered to them. Older birds may become fussy and particular, and also show a regrettable tendency to scatter their food. 
After hours of labour expended in isolating some rare species of cercaria, and collecting and examining the cysts, it is trying in the extreme to see them flying to the four corners of the room with one shake of the bird's head. It is often difficult to induce certain individuals to eat alone if they are used to feeding in a flock, and it is a great saving of time and temper to accustom them to both solitary confinement and solitary meals if an experiment is in view. To sit by while the bird darts fretfully to and fro, ignoring its food and the progressively less viable cysts, imposes a strain on the most patient experimentalist. Recourse to forcible feeding is often unsuccessful as the birds are apt to regurgitate their food if frightened or excited.

\section{Mustela erminea L.}

Keeping stoats in captivity has generally been regarded by zoologists (Krumbiegel, I935) as an exceedingly difficult proposition, but a perusal of the advertisement columns of the Gamekeeper and similar periodicals shows that this is frequently accomplished in less scientific circles.

It was found that the chief difficulties lie in locating the nest and subsequently capturing the litter at the right age for the purpose, namely before the young are old enough to take any nourishment apart from milk. As the breeding season for stoats seems to vary by several weeks or even months with individual pairs, this necessitates a constant watch being kept on the parents. This in turn frequently results in the stoats growing suspicious and moving the nest, or the young if they are born. In a nest situated in an old rabbit warren the parents have succeeded in moving them even while digging operations were in progress.

After capture, the baby stoats were kept at room temperature $\left(60^{\circ} \mathrm{F}\right.$.) in a box filled with hay, the centre cavity of which was lined with flannel. It is essential to arrange the artificial nest in such a way that the animals cannot crawl out of it. This they frequently attempt to do, death from chill invariably resulting if they are successful. On one occasion five young were found dead, lying between the hay and the wooden side of the box.

The stoats were fed every $3 \mathrm{hr}$. during the day from 7 a.m. to Io p.m. with warm cow's milk from a pipette. Even before their eyes are open at about 3 weeks old they begin to chew small pieces of raw rabbit flesh. The amount of meat given was gradually increased until at the age of 4-5 weeks their diet consisted entirely of young rabbit (raw) and one small saucer of milk. At first artificial vitamins were added to this diet, but these were later found to be superfluous. Chilled water was also provided. The stoats rarely bathed, although keepers who have also kept these animals in captivity reported the contrary.

At the age of one month the animals were provided with larger cages, about 4 by $2 \mathrm{ft}$., fronted with wire netting. One end was separated off as a sleeping chamber and filled with hay. The cages were placed on trestles in a small open shed in the garden. 
After a few initial errors with regard to treatment in the early stages, the mortality rate was reduced to about $12 \%$. Two of the stoats are now over 4 years old. As the animals thrive so well on rabbit, it is a simple matter to provide them with raw food which is known to be free from helminths (laboratory reared).

Although it seems improbable that these baby stoats could have become infected with trematodes during the first days of their life, yet the probability cannot be entirely excluded and breeding from these captive specimens is now being attempted. A successful brother and sister mating resulted in the birth of a litter, but the female unfortunately devoured her young.

\section{Hydrobia jenkinsi (Smith) and Littorina rudis (Maton)}

These gastropods are both viviparous, and rearing them in the laboratory has so far presented no difficulty. Mature examples of both species were collected in late summer. Hydrobia jenkinsi was kept in finger bowls in fresh water obtained from a hot tap (therefore considered free from viable helminth ova or miracidia) and fed with a variety of food, from boiled Zostera and lettuce to newspaper and bread. Littorina rudis was kept in a mixture of half sea and half fresh water and fed on Ulva, a substitute for which might be found with advantage, as even with repeated washings in hot water it cannot be regarded with absolute certainty as free from viable helminth ova.

The young of both species were born in the autumn and immediately removed to separate dishes. By the following spring they could be used for infection experiments. The mortality was low, but in Littorina rudis the growth was very uneven and numbers of specimens did not appear to develop at all. The maximum length attained in I 2 months was $9 \mathrm{~mm}$.

\section{Peringia ulvae (Pennant)}

This species was kept under the same conditions as described above for Littorina rudis. Collections were made from various habitats both in England and Scotland. It proved exceedingly difficult to get the species to breed in the laboratory. Peringia ulvae is not viviparous, but lays eggs which give rise to a free-swimming veliger. The nature of the difficulties involved are not properly understood, as at the first attempt large numbers of these veligers were successfully reared to maturity-the snails subsequently surviving 5 years! It has never been possible to repeat these experiments although the laboratory conditions were apparently identical.

The chief period of egg production in the laboratory is in the spring, but a certain number are also laid in the autumn. Hatching takes place about Io days later. Except for the initial experiment referred to above, the veligers have invariably died after a few days of free-swimming life. It is possible that the exceedingly minute organisms which serve as food for these tiny veligers were only present in the water on the one occasion when they were reared successfully. 


\section{Carcinus maenas L.}

This crab, which has been experimentally infected by me with "Ubiquita" cercariae from Peringia ulvae is almost always parasitized in the wild. In working out these trematode life histories it was therefore considered essential to rear the second intermediate host in the laboratory. The crabs were collected from the plankton in the megalopa stage. Each larva was placed in a separate finger bowl, the water of which was changed daily. Food consisted of small pieces of the mantle of mussels (Mytilus edulis L.). The bowls were kept scrupulously clean, all debris such as moults or uneaten food being removed instantly. The crabs attained a maximum size of $3 \mathrm{~cm}$. across the carapace in I2 months. Until they had reached the adult stage they were kept in sea water, but subsequently were gradually accustomed to a mixture of half sea and half fresh water. Penetration with the Ubiquita Group of cercariae from Peringia ulvae was effected more satisfactorily in this medium.

\section{ACKNOWLEDGEMENTS}

I would like to express my gratitude to Dr Marie V. Lebour for her invaluable help in confirming our identifications of Carcinus maenas in the megalopa stage, to $\mathrm{Mr}$ Fred Young for the enormous trouble be took with the management of the stoats, and to Miss Anne Rothschild for her tireless energy in rearing the crabs.

\section{REFERENCES}

Krumbiegel, I., I935. Gefangenhaltung und Farbwechsel der Wiesel. Zool. Garten Leipzig, Vol. vIII, pp. 8-I5.

Palombi, A., I938. Metodi impiegati per lo studio dei cicli evolutivi dei Trematodi digenetici. Materiale per la conoscenza della biologia di Podocotyle atomon (Rud.). Livro fubilar Prof. Travassos, Rio de Janeiro, Brazil, pp. 37I-9.

RothSCHILD, M., I936. Rearing animals in captivity for the study of trematode life histories. I. Larus ridibundus L., the black-headed gull. Fourn. Mar. Biol. Assoc., Vol. xxI, pp. 143-5.

Stunkard, H., I938. The morphology and life cycle of the trematode Himasthla quissetensis (Miller and Northup, I926). Biol. Bull. Vol. Lxxv, No. I, pp. I45-64, 2 pls. 